\title{
INTRODUCTION TO YOGYAKARTA ICONS IN THE GAME OF RUNNING CHALLENGE
}

Angga Adha Nugroho Bonai ${ }^{1}$, Dwi Nugraheny ${ }^{2}$, Harliyus Agustian ${ }^{3}$

Program Studi Teknik Informatika

Departemen Informatika

Sekolah Tinggi Teknologi Adisutjipto Yogyakarta

Jl. Janti, Block-R, Lanud Adisutcipto Yogyakarta

Email : ${ }^{1}$ Anggabonai1994@gmail.com, ${ }^{2}$ henynug@gmail.com, ${ }^{3}$ h4rliyus@gmail.com

\begin{abstract}
Yogyakarta's unique and interesting culture makes Yogyakarta one of the tourist areas frequented by tourists. The introduction of a tourist icon is an interesting thing introduced through technology that is packaged in the form of games, because through children's games / users can be more interested, know, remember the tourist icon compared to reading books. So that in this study a game model is needed that can facilitate children in remembering the tourist icon in Yogyakarta through the Game Running Challenge that is made as attractive as possible. Based on the results of user / children's trials, the Running Challenge game application can make it easy for users who are still children aged 6-10 years to know and know the most famous icons in Yogyakarta besides that it can also be an educational medium that has learning about tour.
\end{abstract}

Keywords : Yogyakarta icon, game, running challenge, windows, learning by doing.

\section{Latar Belakang}

Di era modern saat ini, manusia tidak dapat dipisahkan dengan teknologi. Bahkan para orangtua kebanyakan sudah mengenalkan teknologi kepada anak-anak sejak masih kecil. Hal seperti ini tentu saja memiliki dampak yang baik dan juga buruk terhadap anak. Disamping itu, tidak dapat dipungkiri bahwa anak-anak di zaman sekarang ini lebih dekat dengan teknologi jika dibandingkan dengan anak-anak di tahun 90an. Contohnya anak-anak pada zaman sekarang lebih suka memainkan permainan dalam bentuk digital daripada secara tradisional. Permainan tradisional adalah permainan yang dimainkan oleh anak-anak jaman dulu, yang dimainkan secara berkelompok dan tidak menggunakan media elektronik, sedangkan video game atau permainan modern adalah sebuah permainan (hiburan) yang menggunakan media elektronik dan dapat dimainkan tidak berkelompok.

Beberapa penelitian tentang mempelajari perilaku manusia untuk memahami dan menguasai obyek yang dipelajari manusia. Perangkat pembelajaran diciptakan untuk mempermudah manusia dalam memahami dan menguasai materi belajar. Teknologi informasi sebagai perangkat bantu dalam proses pembelajaran. Animasi multimedia memberikan kesan menyenangkan, membantu proses pembelajaran dalam mengingatnya[1]. Penelitian lainnya menyatakan bahwa game edukasi sangat menarik untuk dikembangkan, salah satu kelebihan utama game edukasi adalah pada visualisasi dari permasalahan nyata. Status game, instruksi, dan tools yang disediakan oleh game akan membimbing pemain secara aktif untuk menggali informasi sehingga dapat memperkaya pengetahuan dan strategi saat bermain [2]. Game dengan tujuan edukasi dapat digunakan sebagai salah satu media edukasi yang memiliki pola pembelajaran learning by doing [3].

Kesimpulan dari materi diatas adalah kebanyakan anak usia dini lebih senang bermain dibandingkan belajar. Maka dari itu game dengan tampilan yang menarik akan diminati. Dengan memanfaatkan kelebihan utama sebuah game yaitu model visualisasi dari keadaan nyata. Game dapat menjadi salah satu sarana yang dapat digunakan untuk membantu anak COMPILER 
dalam proses pembelajaran. Maka dirancang suatu permainan yang dapat memudahkan anak dalam mengingat obyek-obyek wisata yang terdapat di-Yogyakarta melalui sebuah Game Running Challenge yang dibuat dengan tampilan semenarik mungkin dengan animasi dan obyek 2D (dua dimensi) dan 3D (tiga dimensi) agar anak tidak bosan saat bermain.

\section{Metodologi Penelitian}

2.1 Analisa Kebutuhan Sistem

Pada pembuatan aplikasi digunakan hardware dan software. Kebutuhan perangkat lunak dalam pembuatan Game Running Challenge yaitu Sistem Operasi Windows 10 Pro 64bit, Blender Foundation, Adobe Photoshop CC 2017, Adobe Audition CC 2017. Hardware yang dibutuhkan dengan spesifikasi Processor Intel Core i3-6006U (2.0 GHz, 3MB L3 Chace), VGA Card NVIDIA GeForce 940MX, Ram 4 GB DDR4, Harddisk 500GB.

\subsection{Analisa Kebutuhan Data}

Hasil analisa kebutuhan data meliputi kebutuhan ikon sebagai modeling utama dalam halaman bermain, kebutuhan suara agar suasana bermain tidak hening dan font text.

\subsection{Skenario}

Adapun skenario jalannya aplikasi yang dibuat sesuai dengan jalannya aplikasi saat dibuka hingga ditutup.

1. Saat pengguna membuka aplikasi maka yang akan muncul untuk pertama kali adalah nama dari game running challenge lalu halaman logo dan nama pengembang dan Loading game.

2. Menu utama akan tampil setelah halaman loading telah selesai. Pada halaman menu utama terdapat 4 tombol pilihan yaitu mulai, informasi tentang ikon, bantuan dan keluar. Saat menekan tombol mulai maka pengguna akan langsung diarahkan pada halaman loading start terlebih dahulu sebelum memasuki halaman bermain. Tombol informasi tentang ikon memberikan informasi tempat wisata dan kuliner yang paling terkenal di Yogyakarta. Tombol bantuan memberikan informasi tentang cara bermain. Tombol keluar berfungsi untuk menutup aplikasi.

3. Halaman bermain merupakan halaman dimana pengguna akan bermain. Pada saat bermain pengguna dapat mengontrol karakter yang berupa anak kecil laki-laki yang akan berlari melewati rintangan-rintangan seperti traffic cone, papan-papan lalu lintas yang menghalangi jalan dan mengumpulkan koin-koin. Pemain memiliki 3 (tiga) nyawa, setiap 1 (satu) kesalahan maka 1 (satu) nyawa akan berkurang dan saat melakukan 3 (tiga) kali kesalahan maka akan langsung masuk pada halaman game over.

4. Tombol keluar hanya terdapat pada menu utama saja, maka untuk menutup aplikasi hanya dapat dilakukan saat berada dimenu utama.

\subsection{Perancangan Modeling Game Running Challenge}

1. Perancangan Karakter

Pada tahapan ini karakter yang dibuat merupakan karakter berbasis 3D (tiga dimensi) yang akan digunakan nantinya pada Game Running Challenge. Modeling karakter bisa dilihat pada Gambar 1. 


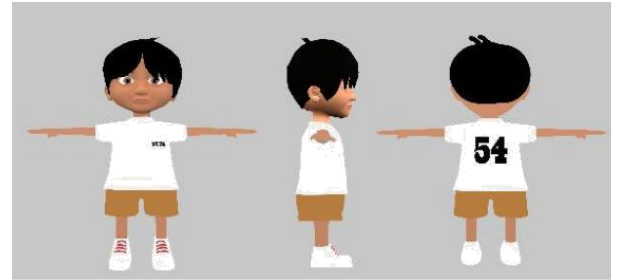

Gambar 1. Perancangan Karakter

\section{Perancangan Ikon}

Santosa (1993) Ikon adalah sesuatu yang melaksanakan fungsi sebagai penanda yang serupa dengan bentuk obyeknya (terlihat pada gambar atau lukisan)[4]. Pada game running challenge ikon dibuat dengan menggunakan 2 (dua) teknik pemodelan yaitu 2D (dua dimensi) dan 3D (tiga dimensi). Contoh beberapa pemodelan dapat dilihat pada Gambar 2.

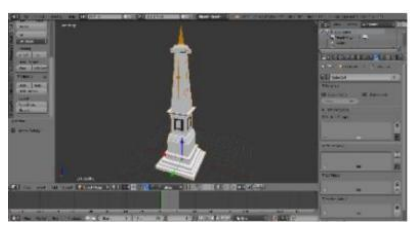

(a)

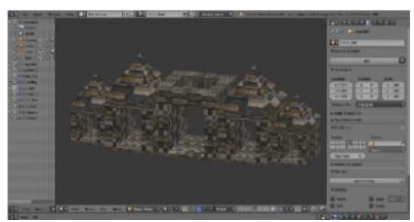

(b)

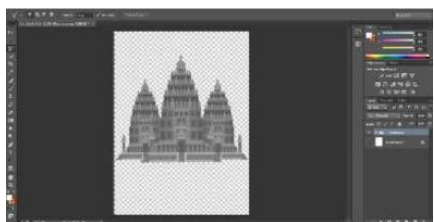

(c)

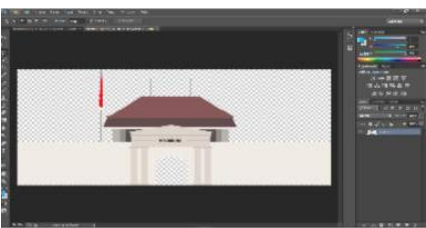

(d)

Gambar 2. Beberapa Perancangan Ikon (a) (b) (c) (d)

Pada Gambar 2 ikon (a) dan (b) merupakan contoh modeling ikon 3D (tiga dimensi) dan pada ikon (c) dan (d) merupakan contoh modeling ikon 2D (dua dimensi). Ikon (a) merupakan modeling 3D (tiga dimensi) tugu golong gilig dan ikon (b) adalah modeling candi ratu boko. Ikon (c) adalah modeling 2D (dua dimensi) candi prambanan dan ikon (d) merupakan modeling bangunan benteng vredeburg.

\section{Perancangan Coin}

Selain ikon, coin merupakan modeling yang memiliki peran penting pada Game Running Challenge. Modeling coin bisa dilihat pada Gambar 3.

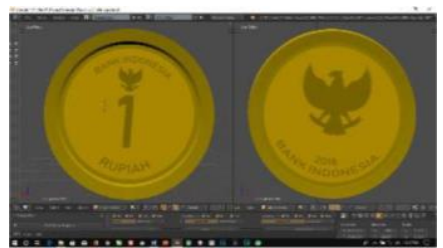

Gambar 3. Perancangan Coin

\section{Perancangan Arena}

Pada tahapan ini akan dibahas proses pembuatan modelling arena yang akan digunakan nantinya pada Game Running Challenge. Perancangan modeling arena bisa dilihat pada Gambar 4. 


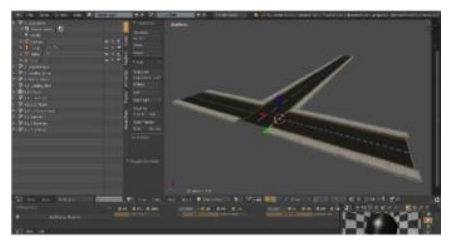

Gambar 4. Perancangan Arena

5. Perancangan Rintangan

Rintangan yang diapakai dalam game running challenge berupa komponen lalu lintas seperti lampu merah, traffic cone dan papan-papan/palang lalu lintas. Beberapa contoh modeling perlengkapan lalu lintas bisa dilihat pada Gambar 5.

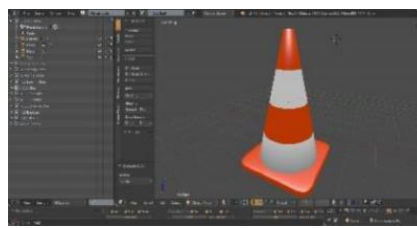

(a)

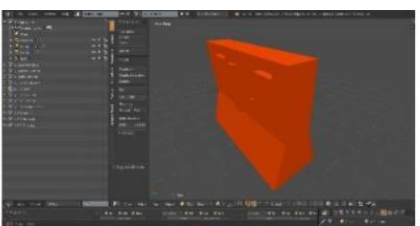

(b)

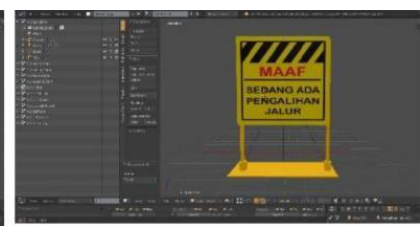

(c)

Gambar 5. Perancangan Beberapa Rintangan (a) (b) (c)

Pada Gambar 5 rintangan (a) merupakan modeling Traffic cone yang berbahan dasar cone dan cube, rintangan (b) adalah orange box yang dibuat dengan bahan dasar cube, dan ikon (c) adalah papan pemberitahuan lalu lintas yang berbahan dasar cube dan cylinder.

\subsection{Konfigurasi BGE (Blender Game Engine)}

Hendratman (2015) software blender adalah software gratis multifungsi yaitu untuk membuat 3D modelling, animasi, video edit, compositing bahkan untuk membuat game. Mode Blender Game mempunyai tujuan sebagai pembangun game sederhana tanpa menggunakan coding serta mempunyai controller yang berisi kumpulan komponen-komponen yang disebut logic editor[5].

\subsection{Perancangan Controller}

Perancangan controller ini berguna agar pengguna dapat memilih dengan cara mengklik menggunakan mouse pada pilihan yang disediakan pada tiap form dan mengendalikan karakter menggunakan keyboard.

\subsection{Konfigurasi Sound}

Sungkono (1999) music adalah sebuah perpaduan bunyi yang mempunyai arti dan memiliki nilai artistic tinggi. Sound effect yang sering disingkat $(F X)$ adalah efek suara adalah suara tiruan atau asli yang menampilkan daya imajinasi dan pengalaman tentang situasi yang sedang ditampilkan[6].

\section{Hasil dan Pembahasan}

\subsection{Penjelasan Aplikasi}

Aplikasi game running challenge merupakan aplikasi game yang dibangun dengan memanfaatkan fitur blender game engine (BGE) yang terdapat pada software blender 
foundation. Blender foundation digunakan sebagai software utama dalam membangun sistem aplikasi dan dibantu oleh 2 (dua) software multimedia milik adobe systems yaitu adobe photoshop dan adobe audition. Adobe photoshop berperan sebagai perancangan texture dan desain dari tiap-tiap form, sedangkan adobe audition digunakan untuk mengolah sound effect (FX) dan backsound.

\section{Halaman Opening}

Halaman opening terbagi menjadi 3 (tiga) bagian yaitu halaman nama game, halaman nama dan logo pengembang dan halaman loading game. Tampilan dari halaman opening bisa dilihat pada Gambar 6.

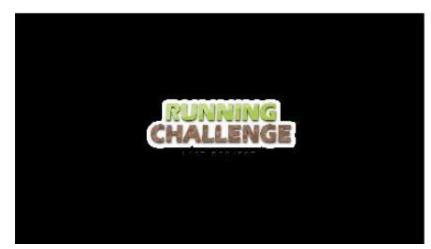

(a)

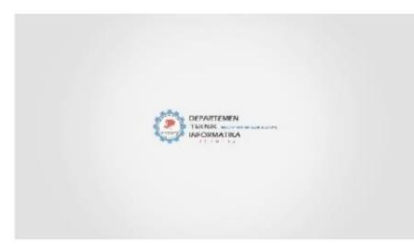

(b)

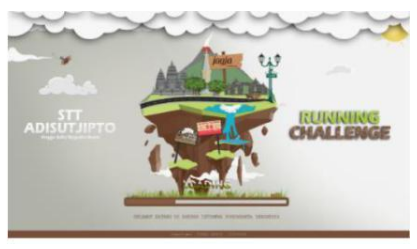

(c)

Gambar 6. Beberapa Tahap Halaman Opening (a) (b) (c)

Pada Gambar 6 form (a) merupakan halaman nama game yang akan tampil terlebih dahulu dengan tampilan nama dari game running challenge last project dengan durasi beberapa detik saat aplikasi dibuka. Form (b) adalah halaman nama dan logo pengembang yang akan tampil dengan waktu jeda beberapa saat setelah halaman nama game. Setelah halaman nama pengembang telah selesai memuat lalu masuk form (c) yaitu halaman loading game yang memakan waktu jeda yang lebih dari waktu jeda nama game dan halaman nama dan logo pengembang. Akan tetapi semua tergantung pada kecepatan atau spesifikasi komputer yang dipakai oleh pengguna.

2. Halaman Penyedia Pilihan dan Informasi

Halaman penyedia pilihan dan informasi mencakup halaman menu utama, informasi tentang ikon dan halaman bantuan seperti yang ditunjukan pada Gambar 7.

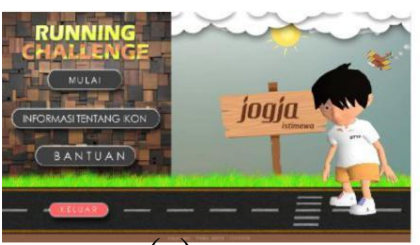

(a)

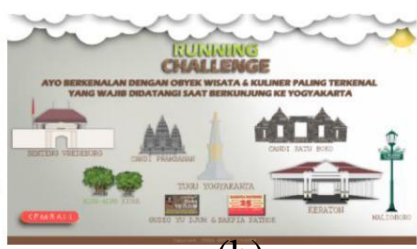

(b)

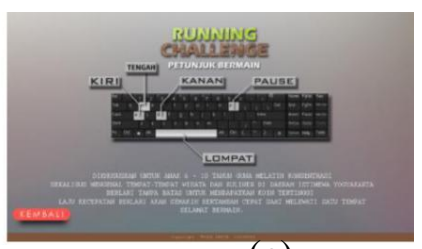

(c)

Gambar 7. Halaman Penyedia Pilihan dan Informasi (a) (b) (c)

Gambar 7 form (a) merupakan tampilan dari halaman menu utama yang berisikan 4 (empat) tombol pilihan yaitu tombol mulai, informasi tentang ikon, bantuan dan keluar. Form (b) merupakan tampilan halaman yang akan muncul saat pengguna menekan tombol informasi tentang ikon yang berada pada halaman menu utama dan form (c) merupakan tampilan halaman informasi bantuan yang akan muncul saat pengguna menekan tombol bantuan yang berada pada menu utama. 


\section{Halaman Bermain}

Halaman bermain akan tampil saat pengguna menekan tombol mulai yang terdapat pada menu utama, halaman bermain mencakup halaman loading start, halaman permainan dan fasilitas pause yang disediakanseperti yang ditunjukan pada Gambar 8 .

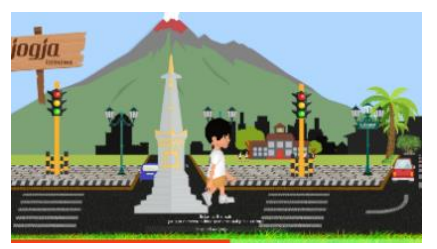

(a)

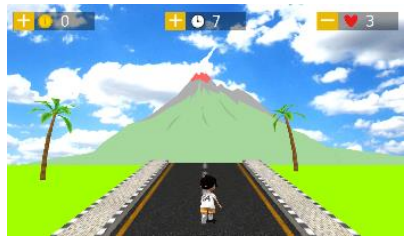

(b)

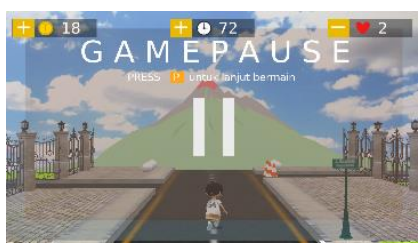

(c)

Gambar 8. Beberapa Halaman Bermain (a) (b) (c)

Gambar 8 form (a) merupakan halaman loading start, setelah halaman loading start selesai memuat lalu masuk pada gambar form (b) yang merupakan halaman bermain, halaman bermain ini merupakan halaman yang inti dari game, karena halaman bermain ini merupakan tujuan dari game ini dibuka atau digunakan, saat bermain pengguna diberikan fasilitas informasi coin yang didapat, informasi waktu yang ditempuh dan health bar dan fasilitas pause yang ditampilkan pada gambar form (c).

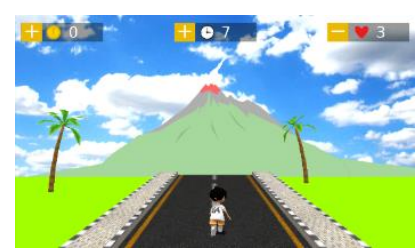

(a)

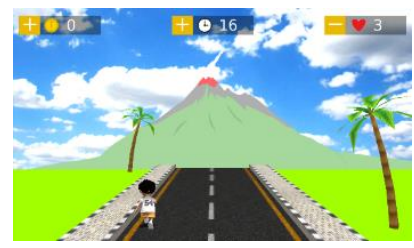

(c)

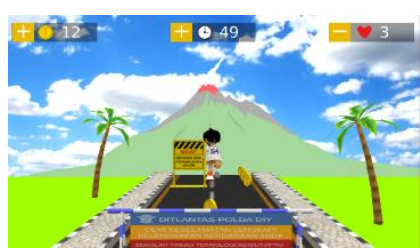

(b)

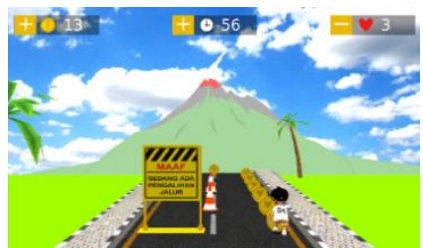

(d)

Gambar 9. Pergerakan Karakter (a) (b) (c) (d) Pada Halaman Bermain

Gambar 9 pergerakan (a) adalah posisi karakter tepat pada bagian tengah lalu pada pergerakan (b) adalah pergerakan karakter saat melompat, pada pergerakan (c) adalah pergerakan karakter kearah kiri dan yang terakhir adalah pergerakan (d) yang merupakan pergerakan kearah kanan yang dikontrol menggunakan tombol d pada keyboard.

Karakter dirancang untuk bergerak dan dikontrol dengan tombol tertentu pada keyboard agar menghindari rintangan, mengambil coin serta mengambil posisi yang tepat saat melewati ikon seperti pada Gambar 10. 


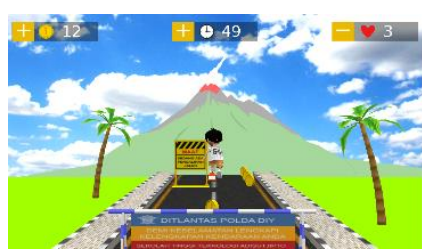

(a)

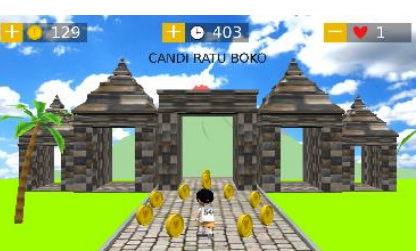

(b)

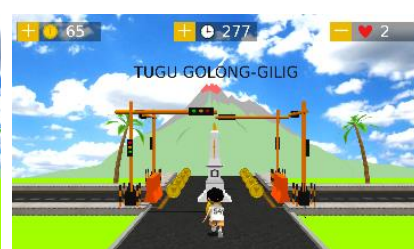

(c)

Gambar 10. (a,b,c) Proses melewati Rintangan dan Ikon

4. Halaman Game Over

Halaman game over akan muncul saat pengguna melakukan 3 (tiga) kali kesalahan saat bermain di halaman bermain. Informasi skor atau coin yang didapat akan tampil pada bagian atas karakter dan terdapat 2 (dua) button pilihan yaitu restart dan menu utama. Halaman game over seperti yang terlihat pada Gambar 11.

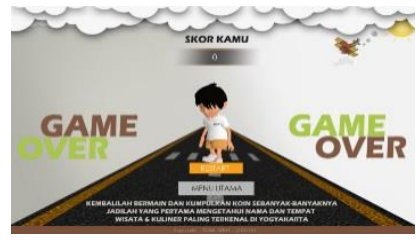

Gambar 11. Halaman Game Over

\subsection{Pengujian Game}

Pengujian merupakan hal terpenting yang bertujuan untuk mengetahui apakah aplikasi yang dibuat sudah berjalan dengan baik atau belum.

\section{Uji Coba Sistem Operasi}

Pada tahap pengujian ini bermaksud untuk mengetahui aplikasi yang dibuat sudah memenuhi kriteria yang sesuai dengan perancangan.

Tabel 1 Uji Coba Aplikasi Pada Sistem Operasi

\begin{tabular}{|c|c|c|c|c|c|c|c|}
\hline \multirow{2}{*}{ No } & \multirow{2}{*}{$\begin{array}{c}\text { Sistem } \\
\text { Operasi }\end{array}$} & Mulai & $\begin{array}{c}\text { Informasi } \\
\text { tentang } \\
\text { ikon }\end{array}$ & Bantuan & Keluar & Restart & $\begin{array}{c}\text { Menu } \\
\text { utama }\end{array}$ \\
\cline { 3 - 8 } & Windows 7 & $\checkmark$ & $\checkmark$ & $\checkmark$ & $\checkmark$ & $\checkmark$ & $\checkmark$ \\
\hline 2 & Windows 8 & $\checkmark$ & $\checkmark$ & $\checkmark$ & $\checkmark$ & $\checkmark$ & $\checkmark$ \\
\hline 3 & Windows 10 & $\checkmark$ & $\checkmark$ & $\checkmark$ & $\checkmark$ & $\checkmark$ & $\checkmark$ \\
\hline
\end{tabular}

Hasil dan kesimpulan yang didapat pada tabel 1 adalah aplikasi dapat berjalan dengan baik pada sistem operasi 7, 8 dan 10 .

\section{Uji Coba Navigasi Game}

Hasil pengujian yang telah dilakukan menyatakan bahwa semua tombol navigasi pada game running challenge telah berfungsi dengan lancar sesuai kebutuhan fungsinya yang ditunjukan pada Tabel 2 . 
Tabel 2 Pengujian Tombol Navigasi Game

\begin{tabular}{|c|l|c|l|}
\hline No & Komponen & Status & \multicolumn{1}{c|}{ Keterangan } \\
\hline 1 & Tombol Mulai & Berhasil & $\begin{array}{l}\text { Ketika dipilih maka akan menuju ke halaman } \\
\text { loading start untuk memulai permainan. }\end{array}$ \\
\hline 2 & $\begin{array}{l}\text { Tombol } \\
\text { Informasi } \\
\text { Tentang Ikon }\end{array}$ & Berhasil & $\begin{array}{l}\text { Ketika dipilih maka akan menuju ke halaman } \\
\text { informasi tentang ikon. }\end{array}$ \\
\hline 3 & $\begin{array}{l}\text { Tombol } \\
\text { Bantuan }\end{array}$ & Berhasil & $\begin{array}{l}\text { Ketika dipilih maka akan menuju ke halaman } \\
\text { informasi tentang controller karakter. }\end{array}$ \\
\hline 4 & Tombol keluar & Berhasil & Ketika dipilih maka game akan tertutup. \\
\hline 5 & Tombol Restart & Berhasil & $\begin{array}{l}\text { Ketika dipilih maka permainan akan dimulai } \\
\text { kembali }\end{array}$ \\
\hline 6 & $\begin{array}{l}\text { Tombol Menu } \\
\text { Utama }\end{array}$ & Berhasil & $\begin{array}{l}\text { Ketika dipilih maka akan menuju ke halaman } \\
\text { menu utama }\end{array}$ \\
\hline 7 & Score & Berhasil & Bertambah ketika karakter menyentuh coin. \\
\hline 8 & Health bar & Berhasil & $\begin{array}{l}\text { Berkurang ketika karakter menabrak } \\
\text { rintangan }\end{array}$ \\
\hline 9 & Sound & Berhasil & Sound yang diberikan berhasil dijalanakan. \\
\hline 10 & Sound effect & Berhasil & $\begin{array}{l}\text { Sound sesuai dengan pergerakan atau } \\
\text { tindakan yang terjadi dalam game. }\end{array}$ \\
\hline
\end{tabular}

Tabel 2 menunjukan bahwa tombol-tombol dalam game dapat dijalankan dengan baik atau berhasil.

3. Uji Coba Tombol Controller

Hasil pengujian yang telah dilakukan menyatakan bahwa semua tombol navigas pada karakter running challenge saat jalannya permainan telah berfungsi dengan lancar sesuai kebutuhan fungsinya yang ditunjukan pada Tabel 3.

Tabel 3 Pengujian Tombol Controller

\begin{tabular}{|c|l|l|l|}
\hline No. & Komponen & Status & \multicolumn{1}{c|}{ Keterangan } \\
\hline 1 & Tombol W & Berhasil & $\begin{array}{l}\text { Ketika ditekan maka karakter akan } \\
\text { memusatkan posisinya tepat ditengah } \\
\text { jalanan }\end{array}$ \\
\hline 2 & Tombol D & Berhasil & $\begin{array}{l}\text { Ketika ditekan maka karakter akan } \\
\text { berpindah posisi ke kanan. }\end{array}$ \\
\hline 3 & Tombol A & Berhasil & $\begin{array}{l}\text { Ketika ditekan maka karakter akan } \\
\text { berpindah posisi ke kiri. }\end{array}$ \\
\hline 4 & Tombol Space & Berhasil & $\begin{array}{l}\text { Ketika ditekan maka karakter akan } \\
\text { melompat. }\end{array}$ \\
\hline 5 & Tombol P & Berhasil & $\begin{array}{l}\text { Ketika ditekan permainan dapat dijeda } \\
\text { dan dilanjutkan kembali. }\end{array}$ \\
\hline
\end{tabular}

Tabel 3 menunjukan bahwa tombol-tombol controller game dapat dijalankan dengan baik atau berhasil 


\subsection{Statistik Hasil Pengujian Kuesioner}

Adapun jumlah responden yang mengisi kuesioner ini sebanyak 30 responden, maka didapatkan hasil pengujian yang tertera pada Gambar 12.

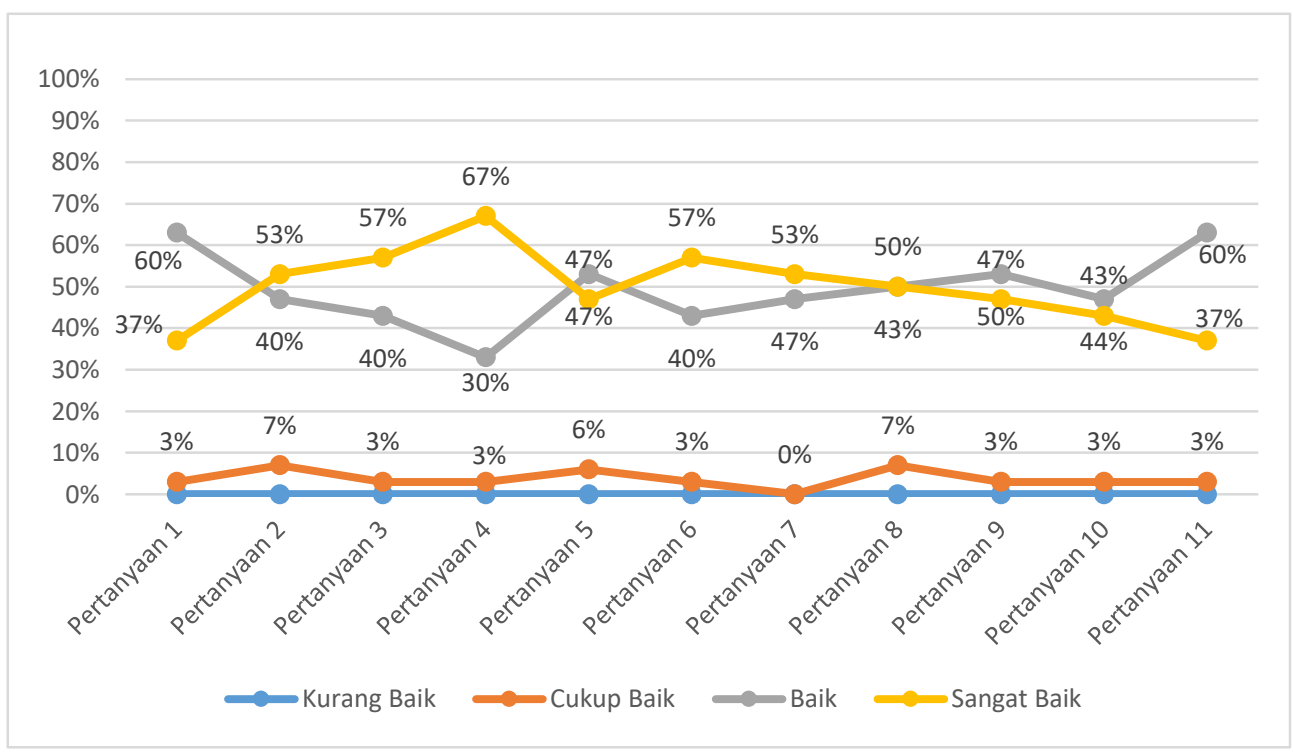

Gambar 12 Statistik Hasil Pengujian Kuesioner

Berdasarkan statistik hasil pengujian kuesioner, maka dapat diambil kesimpulan secara umum bahwa pernyataan yang dilakukan oleh responden rata-rata paling tinggi pada bagian 4 (empat) atau sangat baik.

\section{Kesimpulan}

Berdasarkan hasil analisa pengujian dari game running challenge dapat disimpulkan sebagai berikut:

1. Aplikasi game running challenge dapat memberikan kemudahan penggunaan sistem kepada pengguna yang merupakan anak usia 6 - 10 tahun untuk dapat mengenal dan mengetahui ikon-ikon yang paling terkenal di Yogyakarta lewat sebuah game.

2. Game ini dapat digunakan sebagai salah satu media edukasi yang memiliki pola pembelajaran learning by doing.

3. Berdasarkan 30 responden pengguna (anak-anak) dapat mengetahui objek wisata Yogyakarta setelah bermain game Running Challenge.

\section{Daftar Pustaka}

[1] Suheri, A. (2006). Animasi Multimedia Pembelajaran. Jurnal Media Teknologi, 2(1), 27 33.

[2] Vega Vitianingsih, A. (2016). Game Edukasi Sebagai Media Pembelajaran Pendidikan Anak Usia Dini. Inform, 1(1), 25-32.

[3] Handriyantini, E., \& Kom, S. (2009). Permainan edukatif (educational games) berbasis komputer untuk siswa sekolah dasar. Malang: Sekolah Tinggi Informasi \& Komputer Indonesia. 
[4] Santosa, P. (1993). Ancangan semiotika dan pengkajian susastra. Angkasa.

[5] Hendratman, H. (2015). The Magic of Blender 3D Modelling. Bandung: Informatika.

[6] Sungkono. 1999. Pengembangan Media Audio. Yogyakarta: FIP UNY.

[7] Satria, D. A. (2018). Analisis Perbedaan Genre Game Pada Google Playstore Menggunakan Parameter Tracy Fullerton. Angkasa: Jurnal Ilmiah Bidang Teknologi, 10(1), 97-106.

[8] Atmojo, B. D. (2018). MAKING OF HELICOPTER MODELS WITH POLYGONAL MODELING TECHNIQUES IN MABUR MOTOR GAME WITH 3D BLENDER. Compiler, 7(2), 99-106.

[9] Pratama, D. F., Tamatjita, E. N., \& Nugraheny, D. (2016). Permainan Catur Inggris Berbasis Android Menggunakan Algoritma Minimax. Compiler,5(2).

[10]Prasetyo, E. T., \& Retnowati, N. D. (2015). Penerapan Kecerdasan Buatan Pada Game "Air Strike Stta" Berbasis Client Server Pada Android. Compiler, 4(1).

[11] Hidayat, A., \& Adiputra, B. D. (2015). Perancangan Game Flight Simulator N219 yang Dikendalikan dengan Perangkat Smartphone Android melalui Media Wi-Fi. Compiler, 4(1).

[12] Tamatjita, E. N., Irawaty, M., \& Ramdhani, R. (2016). Sistem Pakar Pada Permainan Untuk Mengukur Tingkat Intelligence Quotient (Iq) Menggunakan Metode Binet-simon Berbasis Android. Compiler, 5(1).

[13] Aryanto, S., Retnowati, N. D., \& Basir, B. (2014). Simulator Kendali Pesawat Terbang Extra 300 L Berbasis3d dengan Metode Simulation Game. Compiler, 3(1). 